\title{
High performance and serviceability of fibre reinforced concrete
}

\author{
P. J. Sasturkar \\ Department of Civil Engineering, PDA College of Engineering, India
}

\begin{abstract}
Ten simply supported grossly under-reinforced tapered concrete beams of full size were tested up to complete collapse under flexural effect .Out of 10 beams, 5 beams were non-fibrous and the remaining beams contained fibres. The beams had a variation in the tapered angle as $2^{\circ}, 4^{\circ}, 6^{\circ}, 8^{\circ}$ and $10^{\circ}$. The concrete mix, conventional steel and the type of fibre used were held constant. Flat corrugated steel fibres were utilized as secondary reinforcement. The strength and stability parameters were measured. It is established that the fibrous tapered beams can be used economically in earthquake prone areas.

Keywords: earthquake, grossly under-reinforced sections, fibre reinforced concrete, tapered beams.
\end{abstract}

\section{Introduction}

Concrete is probably the most widely used man made construction material around the world. The use of different types of fibres in varying shapes and sizes along with the ingredients of concrete was investigated to produce a composite material called 'Fibre Reinforced Concrete' (FRC) or 'Fibrous Concrete'. The progress and economics of construction technology depends on the intelligent use of materials and on the continuous improvement of available materials.

Fibres arrest cracks and increase the tensile strength of concrete as was proved by Romauldi and Batson [1]. The ductility of fibrous beams is also increased as shown by Swamy and Mangat [2], Sasturkar [3] and Kaushik and Sasturkar [4]. Liang and Galvez [5] proved that the peak-load capacity and fracture toughness, as indicator of ductility, were enhanced.

Crack resistance and fracture toughness of fibrous beams is enhanced as shown by Johnston and Gray [6] and Balaguru et al. [7]. Ramakrishnan and 
Lokvik [8] concluded that the flexural fatigue values are increased in fibrous beams. Similar deflection patterns for fully and partially fibrous beam sections were observed as indicated by Nagaraj and Dwarakanath [9]. Reduction of dead weight of a beam by decrease in its dimensions and without too much concession in its load carrying capacity was studied by Fatih et al. [10].

Sufficient work has been carried out on rectangular reinforced concrete (RC) beams containing fibres. No much work has been reported in the literature on tapered beams containing steel fibrous concrete. Hence it is decided to test conventional RC tapered beams which are reinforced with steel fibres.

\section{Experimental programme}

Roof beams used in most of the destroyed residential dwellings in earthquake prone areas were made out of wood. RC can be one of the effective materials for resisting earthquake. Hence the wooden beams are now to be replaced in toto by $\mathrm{RC}$ beams containing fibres. When concrete beams are used as supporting systems the dead load of beams is too high which can be reduced by tapered beams. The thickness of such sections is selected mainly according to the conditions for distributing the reinforcement and to facilitate the placing of concrete. The tapered beams are used for single storeyed dwellings in villages for overlaying the pitched roof materials especially in earthquake prone areas. The beam supports the purlins, roof cladding, solar and roof panels. They can be used for construction of cattle sheds. In the case of occurrence of an earthquake, the human life and cattle can be saved due to the lesser weight of tapered beams and roofing material when compared to non-tapered beams with RC slabs. Hence this study is undertaken.

The pitched roof may consist of simple lightweight fibre panels as roofing material. Since there is no live load acting on roof, these beams are designed as grossly under-reinforced beam sections containing the bare minimum amount of conventional steel reinforcement. This reinforcement is just sufficient to differentiate a RC beam from a plain concrete (PC) beam which does not contain any steel skeleton.

The experimental investigation consisted of casting and testing ten grossly under-reinforced tapered beams of full size having overall span of $2000 \mathrm{~mm}$ and a thickness of $150 \mathrm{~mm}$. The effective span was kept as $1900 \mathrm{~mm}$. These beams were divided in two sets. The first set of 5 beams were non-fibrous (NF) sections whereas the remaining 5 beams contained steel fibres (F) as additional reinforcement. The second set of 5 beams contained fibres up to three-fourth the depth of the beam from the bottom. All the two sets of the beams had the variation in the tapered angle as $2^{\circ}, 4^{\circ}, 6^{\circ}, 8^{\circ}$ and $10^{\circ}$.The numerical following the letters $\mathrm{F}$ or NF denotes the tapered angle. The depth at midspan is kept constant equal to $285 \mathrm{~mm}$ and is varied at the ends for each set of beams to obtain the desired tapered angle.

The steel fibres were supplied by M/s Stewols and Co., Nagpur, India. A constant volume fraction of fibres equal to $1.15 \%$ was used throughout the investigation. The fibres used were 'Shaktiman flat corrugated steel fibres' 
having a rectangular cross section of $2 \mathrm{~mm}$ width and $0.6 \mathrm{~mm}$ thick. They were $25 \mathrm{~mm}$ in length. These fibres were extremely ductile and possess a tensile strength up to $550 \mathrm{MPa}$. The fibres were spread uniformly in the cross section of the beam. The cage reinforcement consisted of two bars of $8 \mathrm{~mm}$ diameter as main steel and two legged $8 \mathrm{~mm}$ diameter stirrups at $195 \mathrm{~mm} \mathrm{c} / \mathrm{c}$ as shear steel. It has been proved in the literature by Thandavamoorthy $[11,12]$ that the newly developed 'Thermo-Mechanically Treated' (TMT) bars have greater ductility performance than the mild steel or deformed bars. Hence TMT bars are used as conventional steel skeleton in the present investigation.

ACC-Suraksha Cement, locally available river sand and crushed Basalt stone aggregate of size $12 \mathrm{~mm}$ and down was used to get M20 grade of concrete mix having the proportion of ingredients as 1:1.50:2.34 with a water- cement ratio of 0.50 . The concrete mix had an adequate workability for both plain and fibrous concrete.

The beams were cured for a period of twenty eight days. They were dried for a period of 24 hours. All the beams were white washed on both faces to mark the propagation of cracks at each successive increment of load. They were then tested up to collapse under flexural loading conditions by applying a single point

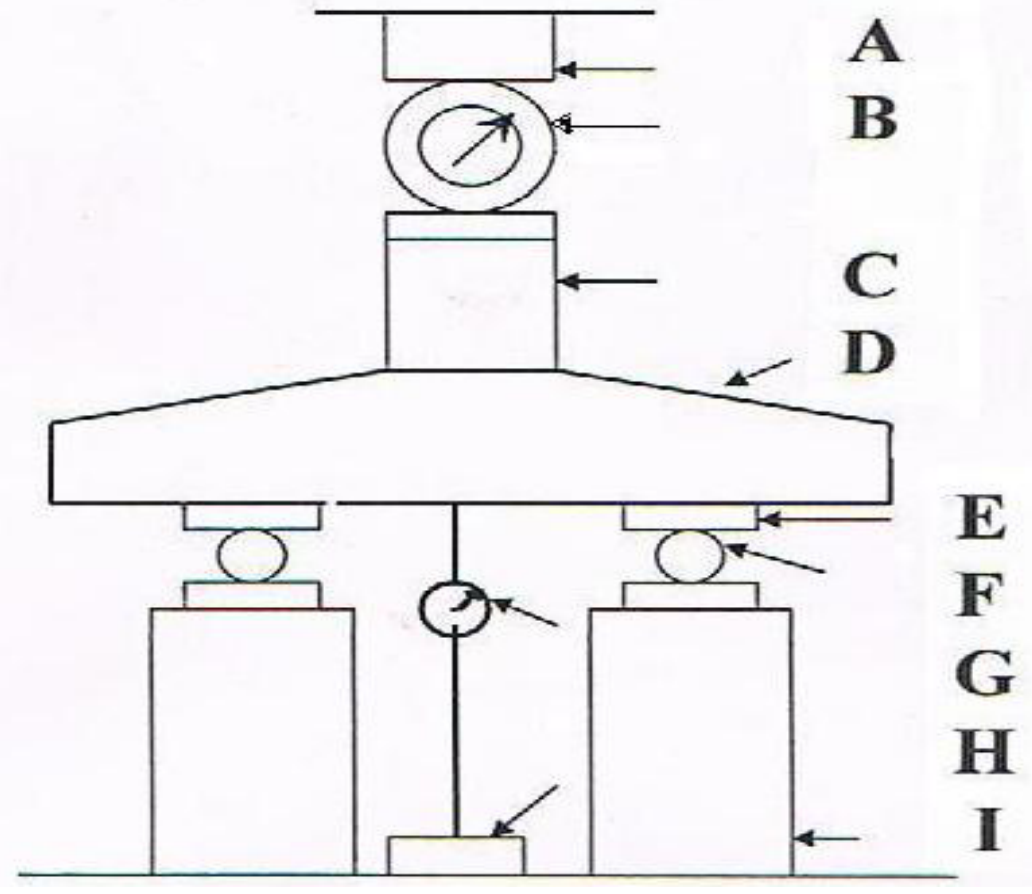

Figure 1: Beam test setup.

load at the centre of the beam as suggested by Pha Yayek et al. [13]. The beams were tested on a $1000 \mathrm{kN}$ capacity loading frame. Baty dial gauges were used to record the deflections at the centre of the beam. 
Figurel shows the loading techniques employed in the present investigation along with the beam test setup. The various accessories used are shown in the figure1 as: A - To loading frame, B - Proving ring, C - Hydraulic jack, D-Tapered beam, E - Bearing plate, F - Roller support, G - Deflectometer, $\mathrm{H}$ - Magnetic base, I - Floor supports.

\section{Results and discussions}

On the basis of investigations carried out in the present study, the various structural properties are listed in Table 1 and Table 2. The notations used in Table 1 and Table 2 are shown in the nomenclature.

Table 1: $\quad$ Load - deflection characteristics of beams.

\begin{tabular}{|c|c|c|c|c|c|}
\hline S. No & T & $\mathrm{P}_{1}(\mathrm{kN})$ & $\mathrm{P}_{2}(\mathrm{kN})$ & $\Delta_{1}(\mathrm{~mm})$ & $\Delta_{2}(\mathrm{~mm})$ \\
\hline 1 & NF2 & 20 & 36 & 0.43 & 10.60 \\
\hline 2 & F2 & 22 & 38 & 0.57 & 20.05 \\
\hline 3 & NF4 & 22 & 30 & 0.74 & 3.81 \\
\hline 4 & F4 & 20 & 39 & 0.85 & 18.53 \\
\hline 5 & NF6 & 18 & 36 & 0.82 & 15.52 \\
\hline 6 & F6 & 20 & 36 & 0.77 & 11.94 \\
\hline 7 & NF8 & 20 & 30 & 1.66 & 7.85 \\
\hline 8 & F8 & 20 & 36 & 0.70 & 18.52 \\
\hline 9 & NF10 & 17 & 29 & 0.69 & 3.37 \\
\hline 10 & F10 & 24 & 36 & 0.95 & 19.46 \\
\hline
\end{tabular}

Table 2: $\quad$ Cracking characteristics of beams.

\begin{tabular}{|c|c|c|c|c|c|}
\hline S. No & T & N & $\mathrm{H}(\mathrm{mm})$ & $\mathrm{S}_{1}(\mathrm{~mm})$ & $\mathrm{S}_{2}(\mathrm{~mm})$ \\
\hline 1 & NF2 & 5 & 250 & 225 & 198 \\
\hline 2 & F2 & 4 & 280 & 215 & 197 \\
\hline 3 & NF4 & 3 & 250 & 230 & 198 \\
\hline 4 & F4 & 10 & 275 & 210 & 108 \\
\hline 5 & NF6 & 9 & 278 & 200 & 139 \\
\hline 6 & F6 & 9 & 275 & 220 & 139 \\
\hline 7 & NF8 & 6 & 250 & 220 & 191 \\
\hline 8 & F8 & 12 & 275 & 240 & 111 \\
\hline 9 & NF10 & 10 & 265 & 200 & 122 \\
\hline 10 & F10 & 8 & 280 & 255 & 174 \\
\hline
\end{tabular}


Table 3: Comparison of load - deflection characteristics of non-fibrous and fibrous beams ( $\%$ increase $+v e, \%$ decrease $-v e)$.

\begin{tabular}{|c|c|c|c|c|c|}
\hline S. No & $\mathrm{T}$ & $\mathrm{P}_{1}(\%)$ & $\mathrm{P}_{2}(\%)$ & $\Delta_{1}(\%)$ & $\Delta_{2}(\%)$ \\
\hline 1 & $\mathrm{~F} 2$ & +10 & +6 & +33 & +90 \\
\hline 2 & $\mathrm{~F} 4$ & -10 & +30 & +15 & +387 \\
\hline 3 & $\mathrm{~F} 6$ & +12 & 0 & -7 & -24 \\
\hline 4 & $\mathrm{~F} 8$ & 0 & +20 & -58 & +136 \\
\hline 5 & $\mathrm{~F} 10$ & +42 & +25 & +38 & +478 \\
\hline
\end{tabular}

\subsection{Comparison of fibrous and non-fibrous beams}

Two companion beams having same tapered angle are compared to each other and the behaviour of fibrous beams is studied with respect to a non-fibrous beam section. The various structural characteristics of fibrous beams are tabulated in Table 3 and Table 4.

Table 4: Comparison of cracking characteristics of non-fibrous and fibrous beams ( $\%$ increase + ve, $\%$ decrease - ve $)$.

\begin{tabular}{|c|c|c|c|c|c|}
\hline S. No. & $\mathrm{T}$ & $\mathrm{N}(\%)$ & $\mathrm{H}(\%)$ & $\mathrm{S}_{1}(\%)$ & $\mathrm{S}_{2}(\%)$ \\
\hline 1 & F2 & -20 & +12 & -5 & -1 \\
\hline 2 & F4 & +233 & +9 & +9 & -46 \\
\hline 3 & F6 & 0 & -1 & +10 & 0 \\
\hline 4 & F8 & +100 & +9 & +10 & -42 \\
\hline 5 & F10 & -20 & +5 & +28 & +43 \\
\hline
\end{tabular}

\subsubsection{Loads}

When two companion fibrous and non-fibrous beams of same angle were compared, it was seen that the load neither increased nor decreased for tapered angle of $8^{\circ} \mathrm{An}$ increase of $10 \%, 12 \%$ and $42 \%$ was noticed in the beam having the tapering of $2^{\circ}, 6^{\circ}$ and $10^{\circ}$, respectively. A reduction of $10 \%$ was observed when the tapered angle was $4^{\circ}$. It was observed that the ultimate load carrying capacity of fibrous beams was increased by $6 \%, 30 \%, 20 \%$ and $25 \%$ for beams with tapered angles of $2^{\circ}, 4^{\circ}, 8^{\circ}$ and $10^{\circ}$, respectively. The load remained constant for the beam of tapered angle of $6^{\circ}$.

\subsubsection{Deflections}

The comparison showed that the deflections increased by $33 \%, 15 \%$ and $38 \%$ for companion fibrous beams of $2^{\circ}, 4^{\circ}$ and $10^{\circ}$, respectively, while the deflections decreased by $7 \%$ and $58 \%$ for companion fibrous beams of $6^{\circ}$ and $8^{\circ}$, respectively. It was observed that the deflection at ultimate load increased 
dramatically by $90 \%, 387 \%, 136 \%$ and $478 \%$ in beams F2, F4, F8 and F10, respectively. However the beam F6 showed a negative trend in its deflection characteristics, the reduction being to an extent of $24 \%$.

\subsubsection{Cracking characteristics}

It was found that the total number of cracks increased dramatically in the case of tapered beams having angle of tapering as $4^{\circ}$ and $8^{\circ}$ by $233 \%$ and $100 \%$, respectively. The reduction in the percentage of total number of cracks observed in the beams F2 and F10 was 20\% in both the cases. There is neither increase nor decrease in the number of cracks in F6. It was found that the maximum height of flexural crack increased marginally by $12 \%, 9 \%, 9 \%$ and $5 \%$ for beams F2, F4, F8 and F10, respectively. There was a marginal reduction of only $1 \%$ in the beam F6. It was observed that the average crack spacing decreased by $46 \%$ and $42 \%$ in the beams F4 and F8, respectively. An increase of $43 \%$ in the average crack spacing was seen in the beam F10. The beam F6 depicted neither increase nor decrease while F2 had a marginal decrease by $1 \%$ in average crack spacing. Similarly, it was noticed that there was an increasing trend in the maximum crack spacing by $10 \%$ for both the beams F6 and F8. The beam F10 showed an increase of $28 \%$. The beams F2 and F4 showed a decrease of $5 \%$ and $9 \%$, respectively.

To summarize, the fibrous beams recorded an optimum increase of $42 \%, 30 \%$ and $38 \%$ in the initial cracking load, ultimate load and deflection at serviceability, respectively.

A dramatic increase of $478 \%$ was noticed in the deflection at ultimate stage over the corresponding non-fibrous companion beam. An optimum increase of $233 \%$ was observed in the total number of cracks. There was an optimum reduction of $46 \%$ in the average crack spacing. There was marginal reduction in the maximum height of flexural crack.

In general, it was observed that all the beams with and without fibres failed in flexural mode only. Most of the cracks were developed in the middle one-third zone of the beam. The structural characteristic property of developing reasonably large number of cracks in the fibrous sets of beams confirmed the law of fracture mechanics.

Further, all the deflection values obtained at initial cracking load were within the permissible limit of serviceability as per IS 456-2000 [14]. As per this IS Code, the permissible value is effective span/250 or $1900 / 250$ or $7.60 \mathrm{~mm}$ in the present investigation. The same limit of serviceability holds good for both fibrous and non-fibrous beam specimens tested under flexural effect. The cracking characteristics and the deflection at ultimate stage was studied on FRC non-tapered beams by the authors Jenq and Shah [15] wherein similar conclusions were drawn as were depicted in the present investigation on tapered beams.

The beams deflect more and more even though the pumping of oil through hydraulic jack is continued. Also there is no further increase in the ultimate load carrying capacity. This happens due to the pullout property of fibres and the beam does not collapse suddenly and there is no catastrophic failure harming the 
inmates of the house. The inmates of the house get ample amount of time and warning to come out of their dwellings comfortably saving their life and property indicating the high quality performance of fibrous tapered beams. Thus it is concluded that the fibrous tapered beams can be used economically in earthquake prone areas looking at its ultimate load-carrying capacity and ultimate deflection performance characteristics even though they are costlier by one and a half times than non-fibrous beams.

A similar performance of FRC was observed by Sasturkar et al. [16-20] by using variety of fibres and hence led to its use in roof beams in earthquake prone areas. The affirmative and rich performance of FRC as is evident from the investigations and discussions in the present paper highlights the sustainable option for the new construction in seismic zone. This new type of construction can be rigorously implemented practically in seismic areas provided the different types of fibres are made commercially available.

\section{Economics}

It would, however, be unrealistic to compare the cost of fibre reinforced concrete with that of conventionally reinforced concrete on the cost of materials alone.

Economics must be also related to performance and serviceability, which are prime functions of designs. The additional cost of the new composite material should therefore be considered in relation to the various advantages that can be achieved.

The rates of various materials are as follows. These rates are based on 2011costs.

$\begin{array}{ll}\text { Cement per } \mathrm{m}^{3} & : \text { U\$ } 98 \\ \text { Fine aggregate per } \mathrm{m}^{3} & : \text { U\$ } 12 \\ \text { Coarse aggregate per } \mathrm{m}^{3} & : \text { U\$ } 7 \\ \text { TMT bars of } 8 \mathrm{~mm} \phi \text { per } \mathrm{kg} . & : \text { U\$ } 1.2 \\ \text { Shaktiman steel fibres per kg } & : \text { U\$ } 1.6\end{array}$

It is clear that the fibrous specimens cost about one and a half times more than non-fibrous one. From the results obtained in this investigation as discussed above, it proves that fibrous concrete is an economical composite material.

\section{Conclusion}

This study of fibrous concrete tapered beams containing conventional steel leads to the following conclusion.

The fibrous tapered beams of tapered angles $4^{\circ}$ and $8^{\circ}$ can be used economically in practice looking at its performance and serviceability characteristics even though they are costlier by one and a half times than nonfibrous beams. 


\section{Nomenclature}

The following symbols were used in this investigation.

$\mathrm{H}$ - Maximum height of flexural crack

$\mathrm{N}-$ Number of cracks

$\mathrm{P}_{1}$ - Initial cracking load

$\mathrm{P}_{2}$ - Ultimate cracking load

$\mathrm{S}_{1}$ - Maximum crack spacing

$\mathrm{S}_{2}$ - Average crack spacing

$\mathrm{T}$ - Type of beam

$\Delta_{1-} \quad$ Deflection at serviceability

$\Delta_{2-} \quad$ Ultimate deflection

\section{Acknowledgements}

The author would like to acknowledge his institute for providing the facilities to carry out the present investigation. P. J. Sasturkar thanks Hitesh, Aniruddha, Ashwini, Radhika, Arundhati and Arpita for their help rendered during the preparation of this paper.

\section{References}

[1] Romauldi, T P and Batson, C B., Behaviour of reinforced cement concrete beams with closely - spaced reinforcement. American Concrete Institute, 6, pp.775-789, 1963.

[2] Swamy, R.N. and Mangat, P.S., The onset of cracking and ductility of steel fibre concrete. Cement and Concrete Research, 5(1), pp.37-53, 1975.

[3] Sasturkar, P J., Ductile performance of SFRC beams. Proc. of the Int. Conf. on Civil Engineering-Indian Institute of Science, Bangalore, pp.102-108, 2001.

[4] Kaushik, S. K. and Sasturkar, P.J. Simply supported steel fibre reinforced concrete beams under combined torsion, bending and shear. Proc. of the Int. Conf. on Recent Developments in Fibre Reinforced Cements and Concretes, London and New York-Elsevier Applied Science Publications. pp.687-698, 1989.

[5] Liang, R Y and Galvez, E., High strength, high denier discrete polymer fibre in cementitious composites. Proc. of the 1st Materials Engineering Congress, Denver, Newyork, pp.894-902, 1990.

[6] Johnston, C. D. and Gray, R. J., Flexural toughness and first-crack strength of fibre reinforced concrete using ASTM standard C1018. RILEM Symposium, FRC-86, Paper Number: 5.1, 1986.

[7] Balaguru, P N, Narahari, R and Patel, M., Flexural toughness of steel fibre reinforced concrete. American Concrete Institute Materials, 89(6), pp.541$545,1992$. 
[8] Ramakrishnan, V and Lokvik, B J., Flexural fatigue strength of fibre reinforced concretes. Proc. of the Int. Workshop held by RILEM, ACI and others, Mainz, Germany, pp.271-287, 1991.

[9] Nagaraj, T.S. and Dwarakanath, H. V., Structural response of partially fibrous concrete beams. ASCE of Structural Division, 110(11), pp.27982812, 1984.

[10] Fatih, A., Tefaruk, H. and Kamuran, A., Experimental investigation of steel fibre reinforced concrete box beams under bending. Materials and Structures, 39(4), pp.459-467, 2006.

[11] Thandavamoorthy, T. S., Static and fatigue of high ductility bars reinforced concrete beams. Materials in Civil Engineering, 1, pp.41-50, 1999.

[12] Thandavamoorthy, T. S., R.C.C. beams with high ductility ribbed barsbehaviour under monotonic loading. Indian Concrete Journal, 4, pp.282 285, 2001.

[13] Pha Yayek, Anilkumar and Bashetty, D.S., Performance of grossly underreinforced tapered beams partially reinforced with flat steel fibres (partIV). B.E.-Project work submitted to Visveswaraya Technological University, Belgaum (Karnataka) -India, 2006.

[14] IS: 456-2000., Indian standard code of practice for plain and reinforced concrete. Bureau of Indian Standards, New Delhi, Clause 23.2, pp.37, 2000.

[15] Jenq, Y. S. and Shah, S P., Crack propagation in fibre reinforced concrete. Structural Engineering, 112(1), pp.15-25, 1986.

[16] Sasturkar, P. J. and Giriraj, S.Fibrous concrete-an economical mitigation of earthquake resistant design for construction of roof beams. Proc. of the Int. Conf. on Disasters and Mitigation. Madras, pp.A3.33-A3.39, 1996.

[17] Sasturkar, P. J., SRFC-A measure to mitigate earthquakes. Proc. of the Int. Conf. on Disaster Management. Guwahati. pp.621-627, 1998.

[18] Sasturkar, P. J., Patil, A S. and Mujawar, S. S., Performance of grossly under-reinforced tapered beams partially reinforced with ultra duracem polypropylene fibres. Proc. of the Structural Engineering Convention-An Int. Meet, Indian Institute of Science, Bangalore, 2005.

[19] Sasturkar, P.J. and Gani, A., FRC-A new construction material to mitigate earthquakes. Proc. of the Int. Conf. on Earthquake Engineering, School of Civil Engineering, SASTRA, Deemed University, Thanjavur, pp.591-596, 2006.

[20] Sasturkar, P. J., Kulkarni, H. V. and Preeti, P., Performance of FRC: A new sustainable option for construction. Proc. of the $7^{\text {th }}$ Int. Congress on Concrete : Constructions's Sustainable Option, University of Dundee, Dundee, Scotland (UK), pp.365-372, 2008. 